\title{
Prevalence, Proportionality, and Cause of Ventilator Alarms in a Pediatric Intensive Care Setting
}

\author{
Leo Langga, Jisoo Oh, David López, Nancy Blake, Edward McField, Justin Hotz, \\ Leonardo Nava-Guerra, Kelby Knox, and Richard Chinnock
}

\begin{abstract}
BACKGROUND: Clinical alarms play an important role in monitoring physiological parameters, vital signs and medical device function in the hospital intensive care environment. Delays in staff response to alarms are well documented as health care providers become desensitized to increased rates of nuisance alarms. Patients can be at increased risk of harm due to alarm fatigue. Current literature suggests alarms from ventilators contribute significantly to nonactionable alarms. A greater understanding of which specific ventilator alarms are most common and the rates at which they occur is fundamental to improving alarm management. METHODS: A retrospective review was performed on alarms that occurred on the Avea and Servo-i ventilators used in the pediatric ICU and pediatric cardiothoracic ICU at a major metropolitan children's hospital. High- and medium-priority alarms, as classified by the manufacturer, were studied between June 1, 2017, and November 31, 2017. Descriptive data analysis and a 2-proportion z-test were performed to identify proportionality, cause, and prevalence rates in the pediatric ICU and the cardiothoracic ICU. RESULTS: Eleven distinct ventilator alarms were identified during 2,091 d of mechanical ventilation. The Inspiratory Flow Overrange alarm $(42.4 \%)$ on the Servo-i, Low $\mathrm{V}_{\mathrm{TE}}(\mathbf{2 0 . 4 \%}$; expiratory tidal volume) and Circuit Integrity alarm $\mathbf{( 2 0 . 0 \% )}$ on the Avea were the most prevalent causes according to ventilator type. Medium-priority alarms comprised $\mathbf{6 8 . 7 \%}$ of all Servo-i alarms, and high-priority alarms comprised $84 \%$ of all Avea alarms. The 2-sample test of proportions was significant for differences between both areas $(P<.001)$. The overall alarm prevalence rate was 22.5 ventilator alarms per ventilator-day per patient. CONCLUSIONS: The cause and proportion of alarms varied by ventilator and care unit. High-priority alarms were most common with the Avea and medium-priority alarms for the Servo-i. The overall combined ventilator alarm prevalence rate was $\mathbf{2 2 . 5}$ alarms per ventilator-day per patient. Key words: ventilator alarms; frequency; prevalence; proportionality; cause; rate; alarm fatigue; critical alarm; alarm priority; pediatric intensive care unit. [Respir Care 2021;66(4):541-550. (C) 2021 Daedalus Enterprises]
\end{abstract}

\section{Introduction}

Clinical alarms and physiologic monitors are pervasive and are an established part of critical care in the hospital

Dr Langga and Mr Hotz are affiliated with the Department of Respiratory Care, Children's Hospital Los Angeles, Los Angeles, California. Drs Langga, Oh, and Chinnock are affiliated with the School of Public Health, Health Policy and Leadership, Loma Linda University, Loma Linda, California. Mr Hotz, Dr Nava-Guerra, and Mr Knox are affiliated with the Anesthesia Critical Care Medicine, Children's Hospital Los Angeles, Los Angeles, California. Mr Knox is affiliated with the University of Southern California, Los Angeles, California. Dr Lopéz is affiliated with the Department of Cardiopulmonary Sciences, School of Allied Health setting. The goal of physiologic monitors and clinical alarms is to provide early warnings to redirect attention to a potential impending critical event, thereby allowing early intervention and prevention of a critical event. ${ }^{1}$ Physiologic

Profession, Loma Linda University, Loma Linda, California. Dr Blake is affiliated with the Harbor UCLA Medical Center, Torrance, California. Dr McField is affiliated with the Center for Community Health Policy, Loma Linda, California. Dr Nava-Guerra is affiliated with the Medtronic, Los Angeles, California. Dr Chinnock is affiliated with the Loma Linda University Children's Hospital, Loma Linda, California.

Dr Langga presented a version of this paper at AARC Congress 2019, held November 9-12, 2019, in New Orleans, Louisiana. 


\section{Ventilator Alarms in Pediatric Intensive Care}

monitors provide audible and visual alerts as parameters move outside of set alarm thresholds.

Many medical devices also possess their own monitoring alarm systems. For example, ventilators, intravenous infusion pumps, feeding pumps, hospital beds, and other medical

See the Related Editorial on Page 699

devices have their own unique alarms adding to the milieu of sounds that are seen, heard, and experienced in the hospital setting. Some medical devices are highly complex. A few ventilators offer $>100$ different types of alarms. ${ }^{2}$ In addition, there are large proportions of nonactionable clinical alarms that do not require clinical intervention and contribute to what has been described as alarm fatigue. ${ }^{3-6}$ The ubiquitous prevalence of alarms can cause caregivers to become desensitized, exhibited through delayed or ignored responses to ventilator alarms in the ICU. ${ }^{7-9}$

Ventilator alarms may contribute to alarm fatigue by adding to the total number of nonactionable alarms. Ventilator alarms comprise $16-45 \%$ of all clinical alarms generated in the operating room setting. ${ }^{3,10}$ A large proportion of ventilator-specific alarms (as high as $73 \%$ in the adult ICU) are nonactionable. ${ }^{11}$ The high proportion of nonactionable ventilator alarms is closely connected to the current issues surrounding alarm fatigue and patient safety.

The concern with alarm safety is at the forefront of regulatory agencies, professional organizations, and patient safety organizations. The Emergency Care Research Institute (ECRI) highlighted the danger of excessive nonactionable alarms by reporting alarm fatigue as their number one safety concern for 2 successive years in 2012 and 2013. Further, ECRI reported health technology hazards related to alarm alert and notification overload as one of their top 10 concerns for $2020 .{ }^{12}$ For more than a decade, the Joint Commission and FDA, a government regulatory agency that establishes regulations and standards and provides oversight for medical devices, have drawn attention to alarm safety as a concern through their official communications, safety initiatives, and recommendations. In 2003, the Joint Commission highlighted alarm safety as a National Patient Safety Goal and raised the concern even higher through the 2013 Joint Commission Sentinel Report. ${ }^{13}$ Ninety-eight alarmrelated events were reported to have occurred nationally between 2009 and 2012; 80 of these cases ended in

The authors have disclosed no conflicts of interest.

Correspondence: Leo Langga RRT RRT-NPS MBA DrPH.

E-mail: leolangga@gmail.com.

DOI: $10.4187 /$ respcare. 07200

\section{QUICK LOOK}

\section{Current knowledge}

Ventilator alarms make up a large segment of all clinical alarms in the pediatric ICU and have added to the overall burden of alarm fatigue. However, alarm characteristics such as prevalence rates, proportions, and causes are not well understood. Very little has been published on alarm management practices and guidelines. Understanding ventilator alarm characteristics could be an important first step in an evidence-based approach to develop policies for alarm management.

\section{What this paper contributes to our knowledge}

Ventilator alarms occurred in pediatric ICUs at a prevalence rate of 22.5 ventilator alarms per day of mechanical ventilation. The most common ventilator alarms were related to high inspiratory flow, high respiratory frequency and high airway pressures. Ventilator alarm proportions were significantly different between the brands of ventilators.

death. ${ }^{13}$ In 2010, the FDA received 2,500 ventilatorrelated adverse event reports, and approximately 33\% were found to be due to alarm-related issues. ${ }^{14}$ No recent studies were available on ventilator-related injuries.

As health care organizations strive for zero patient harm, one clinical alarm- or medical error-related death is too many. ${ }^{15}$ A single ventilator alarm incident can result in patient demise and be a tragedy for the patient, family, staff, and organization. Ventilator alarms can add a significant burden to the concerns surrounding alarm fatigue. Understanding ventilator alarm characteristics such as alarm rates, proportionality, and variations due to ventilator design are some of the fundamental details needed to enhance alarm safety. The purpose of this study was to determine the frequency, prevalence rates, and cause of high- and medium-priority ventilator alarms. This new knowledge can help policymakers be more strategic in developing alarm practice standards that are directed at the most common types of alarms. Lastly, manufacturers can utilize these findings in the design of more effective and consistent alarm systems to help reduce the overall alarm burden caused by ventilator alarms.

\section{Methods}

A retrospective study was performed on ventilator alarm occurrences for 2 common types of ventilators used in the pediatric ICU (PICU) and pediatric cardiothoracic intensive care unit (CTICU) between June 1, 2017, and November 31, 2017 (110 d) at Children's Hospital Los Angeles, a major 


\section{Ventilator Alarms in Pediatric Intensive Care}

Table 1. Ventilator Alarm Parameter Settings

\begin{tabular}{ll}
\hline \hline \multicolumn{1}{c}{$\begin{array}{c}\text { Ventilator Alarm } \\
\text { Parameter }\end{array}$} & \multicolumn{1}{c}{ Alarm Settings } \\
\hline High Pressure Limit & $10-15 \mathrm{~cm} \mathrm{H}_{2} \mathrm{O}$ above peak inspiratory pressure \\
Low Pressure Limit & $5 \mathrm{~cm} \mathrm{H}_{2} \mathrm{O}$ below peak inspiratory pressure \\
Low $\dot{\mathrm{V}}_{\mathrm{E}}$ & $\begin{array}{l}\text { Greater than half of the patient's measured } \dot{\mathrm{V}}_{\mathrm{E}} \\
\pm 10 \% \text { of baseline }\end{array}$ \\
$\mathrm{F}_{\mathrm{IO}_{2}}$ & \\
\hline $\begin{array}{l}\text { Bedside clinician's clinical judgment is used for setting ventilator alarm parameters not stated in } \\
\text { the policy. }\end{array}$ \\
$\dot{\mathrm{V}}_{\mathrm{E}}=$ minute ventilation \\
\hline
\end{tabular}

metropolitan children's hospital in Los Angeles, California. Study approval was obtained from the institutional review boards at Children's Hospital Los Angeles and Loma Linda University. Collected data included ventilator alarm information for the Avea ventilator (Carefusion, San Diego, California) and the Servo-i ventilator (Maquet, Rastatt, Germany) gathered through the proprietary Philips monitor alarm audit tool (Philips IntelliVue PIIC iX system, Amsterdam, Netherlands).

The ventilator alarm log report included Apnea, Circuit Integrity, High Airway Respiratory Rate (awRR), High peak inspiratory pressure $\left(\mathrm{P}_{\mathrm{aw}}\right)$, High Minute Ventilation $\left(\dot{\mathrm{V}}_{\mathrm{E}}\right)$, High Tidal Volume $\left(\mathrm{V}_{\mathrm{T}}\right)$, Low Peak Pressure $\left(\mathrm{P}_{\text {peak }}\right)$, Low PEEP, Low Exhaled $\mathrm{V}_{\mathrm{T}}\left(\mathrm{V}_{\mathrm{TE}}\right)$, Low/High $\dot{\mathrm{V}}_{\mathrm{E}}$, and Inspiratory Flow Overrange. Circuit Integrity and Inspiratory Flow Overrange alarms were proprietary alarms unique to the Avea ventilator and the Servo-i, respectively, and both alarms were determined by manufacturer software algorithms. The Circuit Integrity alarm on the Avea was activated when the ventilator sensed a circuit occlusion condition on the inspiratory or expiratory limb. The Inspiratory Flow Overrange alarm on the Servo-i occurred when a combination of parameter settings created a condition outside of the allowable inspiratory flow range. For example, in the infant mode, if the subject required inspiratory flows exceeding $33 \mathrm{~L} / \mathrm{min}$, the Inspiratory Flow Overrange alarm was activated.

The standard clinical policy and procedure for setting ventilator alarms was followed for this study, and no modifications were made during this study period. Institutional ventilator alarm policy consisted of high pressure limit set at $10-15 \mathrm{~cm} \mathrm{H}_{2} \mathrm{O}$ above peak inspiratory pressure; low pressure limit at $5 \mathrm{~cm} \mathrm{H}_{2} \mathrm{O}$ below peak inspiratory pressure; low $\dot{\mathrm{V}}_{\mathrm{E}}$ at not less than one half of the patient's measured $\dot{\mathrm{V}}_{\mathrm{E}}$; and $\mathrm{F}_{\mathrm{IO}_{2}} \pm 10 \%$ of baseline (Table 1). The bedside clinician's clinical judgment was used to determine appropriate alarm parameter settings for alarms not covered in policy.

During the study, the Servo-i ventilator was the favored ventilator in the CTICU due to staff comfort and familiarity. The Avea was preferred for the PICU because of its
Table 2. Manufacturer Alarm Priority Classification for the Avea and Servo-i Ventilators

\begin{tabular}{|c|c|c|}
\hline Alarm Description & High Priority & Medium Priority \\
\hline Apnea & Servo-i, Avea & \\
\hline Circuit Integrity & Avea & \\
\hline High $\mathrm{V}_{\mathrm{T}}$ & Avea & \\
\hline Low $P_{\text {peak }}$ & Avea & \\
\hline Low $V_{\mathrm{TE}}$ & Avea & \\
\hline $\mathrm{P}_{\mathrm{aw}}$ High & Servo-i, Avea & \\
\hline High/Low PEEP & Avea (low PEEP) & Servo-i \\
\hline High/Low awRR & & Servo-i, Avea \\
\hline High $\dot{V}_{\mathrm{E}}$ & Servo-i & Avea \\
\hline Low $\dot{V}_{\mathrm{E}}$ & Servo-i, Avea & \\
\hline Inspiratory Flow Overrange & & Servo-i \\
\hline \multicolumn{3}{|c|}{$\begin{array}{l}\text { Classification of medium- and high-priority ventilator alarms were based on the manufacturers' } \\
\text { designations. The low and high values for the alarms vary significantly based on patient size } \\
\text { such as infant, pediatric, or adult, which makes it difficult to establish ranges for all parameters. } \\
\text { Published recommended alarm references/guidelines for ranges are nonexistent. }{ }^{17} \\
\mathrm{~V}_{\mathrm{T}}=\text { tidal volume } \\
\mathrm{P}_{\text {peak }}=\text { peak pressure } \\
\mathrm{V}_{\mathrm{TE}}=\text { expiratory tidal volume } \\
\mathrm{P}_{\mathrm{aw}}=\text { high peak inspiratory pressure } \\
\text { awRR = airway respiratory rate (breathing frequency) } \\
\dot{\mathrm{V}}_{\mathrm{E}}=\text { minute ventilation }\end{array}$} \\
\hline
\end{tabular}

ability to measure transpulmonary pressure. The Servo-i ventilator was also used in the PICU. Patients admitted to the PICU on ventilators other than the Avea or Servo-i ventilators were excluded from the study due to technical limitations on data collection (ie, the Sensormedics 3100a, Sensormedics $3100 \mathrm{~b}$, and home ventilators did not have the capability to interface with the Philips middleware and data collection system).

Data analysis was performed using Matlab (version 9.4, MathWorks, Natick, Massachusetts) and Microsoft Excel (Microsoft, Redmond, Washington) to quantify ventilator alarm frequency, prevalence rate, proportionality, and type of alarms activated according to clinical settings and alarm priority. The alarm priority designation of low-, medium-, and high-priority alarms was determined according to the manufacturers' interpretation of existing guidance, requirements, and recommendations from the FDA. Professional organizations such as the American Association for Respiratory Care (AARC) provided expert opinion through a ventilator consensus statement. ${ }^{16}$ Collected alarm data were also analyzed in subgroups based on the 2 different types of ventilators. A 2-sample z-test of proportions between the PICU and the CTICU was performed to identify differences in alarm prevalence rates for common ventilator alarms.

\section{Results}

The PICU and CTICU alarm log identified 11 unfiltered types of ventilator alarms. These 11 distinct alarms were 
Table 3. Frequency of Alarm Types in the Pediatric ICU and Cardiothoracic ICU

\begin{tabular}{|c|c|c|c|}
\hline Alarm Type and Priority Classification* & Pediatric ICU & Cardiothoracic ICU & Combined ICUs \\
\hline High $\dot{V}_{\mathrm{E}}($ Avea-M) & $68(0.3)$ & NA & $68(0.1)$ \\
\hline Low $\dot{\mathrm{V}}_{\mathrm{E}}($ Avea-H) & NA & NA & NA \\
\hline Low $\mathrm{P}_{\text {peak }}($ Avea-H) & $337(1.3)$ & NA & $337(0.7)$ \\
\hline High $\mathrm{V}_{\mathrm{T}}($ Avea-H) & $1,087(4.0)$ & NA & $1,087(2.3)$ \\
\hline Circuit Integrity (Avea-H) & $1,304(4.8)$ & NA & $1,304(2.8)$ \\
\hline Low $\mathrm{V}_{\mathrm{TE}}($ Avea-H) & $1,312(4.9)$ & NA & $1,312(2.8)$ \\
\hline Low/High $\dot{\mathrm{V}}_{\mathrm{E}}$ (Servo-H) & $1,864(6.9)$ & $872(4.3)$ & $2,736(5.8)$ \\
\hline Apnea (Servo-H, Avea-H) & $2,498(9.3)$ & $1,029(5.1)$ & $3,527(7.5)$ \\
\hline Low PEEP (Avea-H, Servo-M) & $2,538(9.4)$ & $1,667(8.3)$ & $4,205(8.9)$ \\
\hline High $\mathrm{P}_{\text {aw }}($ Servo-H) & $2,859(10.6)$ & $4,050(2.1)$ & $6,909(14.7)$ \\
\hline High awRR (Servo-M, Avea-M) & $4,934(18.3)$ & $3,436(17.1)$ & $8,370(17.8)$ \\
\hline Inspiratory Flow Overrange (Servo-M) & $8,174(3.3)$ & $9,070(45.1)$ & $17,244(36.6)$ \\
\hline Total alarms by unit & 26,975 & 20,124 & 47,099 \\
\hline Ventilator days by unit & 1,083 & 1,008 & 2,091 \\
\hline Alarms per ventilator day & 24.9 & 20.0 & 22.5 \\
\hline \multicolumn{4}{|c|}{$\begin{array}{l}\text { Data are presented as no. }(\%) \text { or no. } \\
\text { * Priority classification: } \mathrm{M}=\text { medium; } \mathrm{H}=\text { high. } \\
\text { Not applicable for the Avea ventilator. } \\
\dot{\mathrm{V}}_{\mathrm{E}}=\text { minute ventilation; } \mathrm{NA}=\text { not applicable; } \mathrm{P}_{\mathrm{peak}}=\text { peak pressure; } \mathrm{V}_{\mathrm{T}}=\text { tidal volume; } \mathrm{V}_{\mathrm{TE}}=\text { expiratory tidal volume; } \mathrm{P}_{\text {aw }}=\text { high peak inspiratory pressure; awRR = airway respiratory rate (breath- } \\
\text { ing frequency). }\end{array}$} \\
\hline
\end{tabular}

classified as medium-priority or high-priority ventilator alarms specific to the Avea and Servo-i during 2,091 d of mechanical ventilation (Table 2). A ventilator day was defined as any portion of a $24-\mathrm{h}$ period requiring mechanical ventilation. A total of 47,099 ventilator alarm conditions were included in this analysis.

\section{Prevalence Rate of Ventilator Alarms}

The combined PICU and CTICU incidence rate of ventilator alarms was 22.5 ventilator alarms per day of mechanical ventilation per patient measured over 2,091 d (Table 3). The PICU had 24.9 ventilator alarms per day of mechanical ventilation and the CTICU had a rate of 20.0 ventilator alarms per day of mechanical ventilation (Table 3). The ventilator alarm prevalence rate for the PICU was greater than that for the CTICU.

\section{Proportionality of Ventilator Alarms}

Overall, the Inspiratory Flow Overrange $(36.6 \%)$ on the Servo-i, High awRR (17.8\%), and High $\mathrm{P}_{\text {aw }}(14.7 \%)$ alarms were the 3 most common ventilator alarms (Fig. 1, Table 3). The Inspiratory Flow Overrange alarm is determined by the ventilator algorithm on the Servo-i. The 2 most common alarms, Inspiratory Flow Overrange and High awRR, were classified as medium-priority alarms and comprised $54 \%$ of all alarms. In general, medium-priority alarms comprised $61.5 \%$ of all ventilator alarms, and high-priority alarms consisted of $38.5 \%$ of all ventilator alarms. The most common high-priority alarms were the High $\mathrm{P}_{\mathrm{aw}}$ and Apnea alarms on the Servo-i.

The High $\dot{\mathrm{V}}_{\mathrm{E}}(0.1 \%)$, Low $\mathrm{P}_{\text {peak }}(0.7 \%)$, and High $\mathrm{V}_{\mathrm{T}}$ $(2.3 \%)$ alarms were the least common ventilator alarms for both PICU and CTICU combined areas. The proportion of other alarms were Circuit Integrity $(2.8 \%)$ and Low $\mathrm{V}_{\mathrm{TE}}$ (2.8\%) alarms, specific to the Avea ventilator only, and the Low/High $\dot{V}_{\mathrm{E}}(5.8 \%)$, Apnea $(7.5 \%)$, and Low PEEP $(8.9 \%)$ alarms for both ventilators.

\section{Ventilator-Specific Results}

The Servo-i had a larger number of medium-priority alarms (68.7\%) (Table 3). The Inspiratory Flow Overrange was the most common type of alarm for the Servo-i (42.4\%), followed by the High awRR (18.2\%) and High $\mathrm{P}_{\mathrm{aw}}(17.0 \%)$ alarms. The Avea had a greater number of high-priority alarms (84.0\%) (Table 4). Circuit Integrity (20.0\%) and Low $\mathrm{V}_{\mathrm{T}}(20.4 \%)$ were the most common alarms for the Avea. The Circuit Integrity alarm in the Avea is predetermined by algorithms programmed by the manufacturer.

The proportion of high- and medium-priority alarms, based on the type of ventilator, varied between the Avea and Servo-i ventilators (Table 4). The proportion of high- and medium-priority alarms with the Avea were $84 \%$ and $16 \%$, respectively. Subsequently, the proportion for high- and medium-priority alarms for the Servo-i were $31.2 \%$ and $68.7 \%$, respectively. Eight different types of alarms were reported for the Avea, and 6 distinct types of ventilator alarms were reported for the Servo-I; 4 types of alarms were common in both ventilators: Apnea, High $\dot{\mathrm{V}}_{\mathrm{E}}$, Low PEEP, and High awRR. 


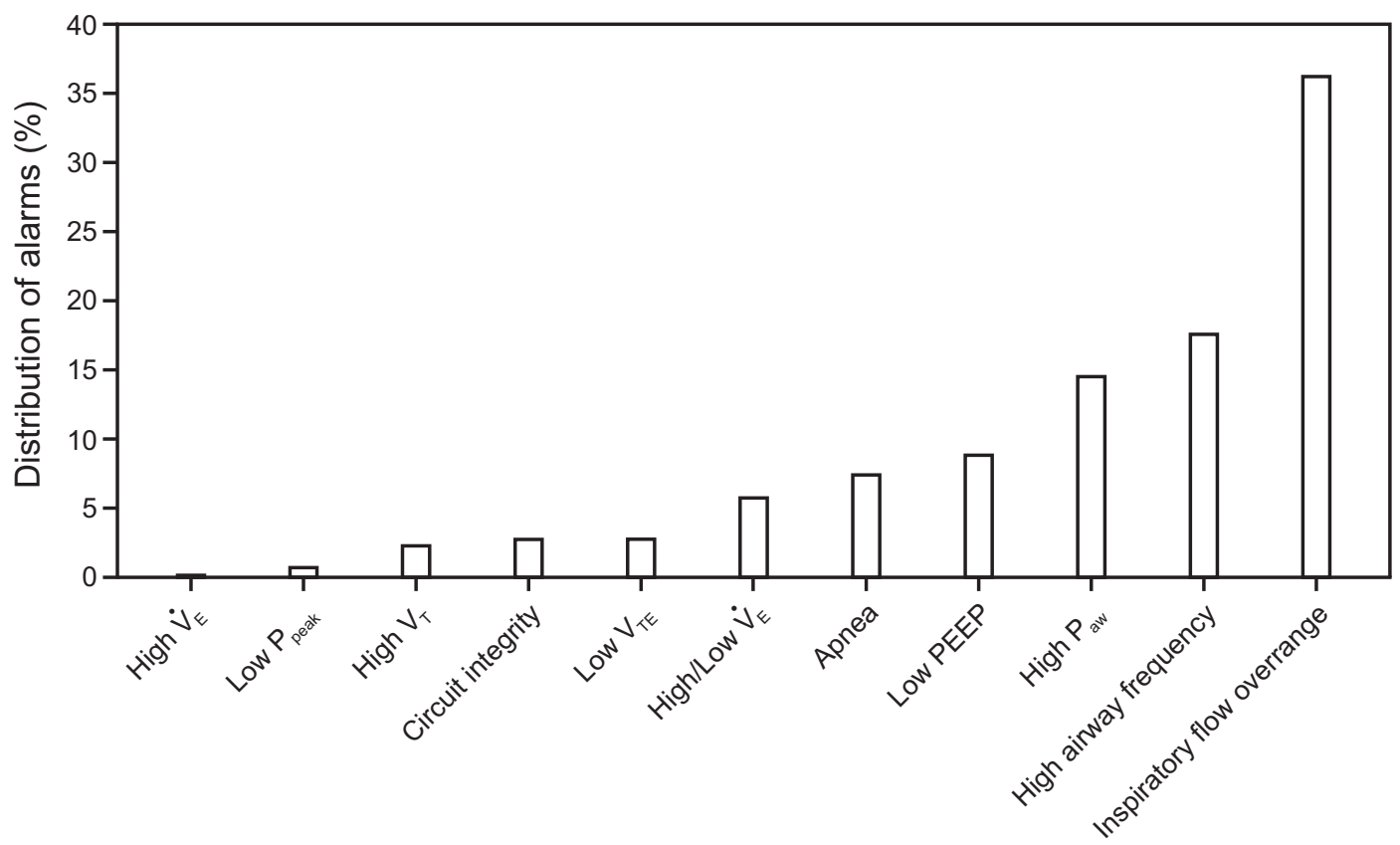

Fig. 1. Distribution of types of ventilator alarms in the pediatric ICU and cardiothoracic ICU. $\dot{V}_{E}=$ minute ventilation; $P_{\text {peak }}=$ peak pressure; $V_{T}$ $=$ tidal volume; $\mathrm{V}_{\mathrm{TE}}=$ end-tidal volume; $\mathrm{P}_{\mathrm{aw}}=$ high peak inspiratory pressure.

Table 4. Alarm Frequency and Priority by Ventilator

\begin{tabular}{|c|c|c|c|c|}
\hline \multirow{2}{*}{ Alarm Type } & \multicolumn{2}{|c|}{ Avea } & \multicolumn{2}{|c|}{ Servo-i } \\
\hline & no. $(\%)$ & Alarm Priority & no. $(\%)$ & Alarm Priority \\
\hline High $\mathrm{P}_{\mathrm{aw}}$ & \multicolumn{2}{|c|}{ NA } & $6,907(17.0)$ & High \\
\hline High $\dot{\mathrm{V}}_{\mathrm{E}}($ Avea $)$ & $68(1.1)$ & Medium & \multicolumn{2}{|c|}{ NA } \\
\hline Low/High $\dot{V}_{\mathrm{E}}($ Servo-i) & & & $2,736(6.7)$ & High \\
\hline Low $\mathrm{P}_{\text {peak }}$ & $335(5.2)$ & High & \multicolumn{2}{|c|}{ NA } \\
\hline Apnea & $462(7.2)$ & High & $3,065(7.5)$ & High \\
\hline Low PEEP & $922(14.3)$ & High & $3,283(8.1)$ & Medium \\
\hline High awRR & $959(14.9)$ & Medium & $7,411(18.2)$ & Medium \\
\hline High $V_{T}$ & $1,087(16.9)$ & High & \multicolumn{2}{|c|}{ NA } \\
\hline Circuit Integrity & $1,283(20.0)$ & High & \multicolumn{2}{|c|}{ NA } \\
\hline Low $V_{\mathrm{TE}}$ & $1,311(20.4)$ & High & \multicolumn{2}{|c|}{ NA } \\
\hline Inspiratory Flow Overrange & \multicolumn{2}{|c|}{ NA } & \multirow[t]{2}{*}{$17,236(42.4)$} & \multirow[t]{2}{*}{ Medium } \\
\hline Total Alarms & \multicolumn{2}{|c|}{6,427} & & \\
\hline
\end{tabular}

\section{2-Proportion z-Test}

A 2-proportion z-test was performed for the 6 types of ventilator alarms present on both the Servo-i and Avea ventilators. The prevalence of alarms was compared between the PICU and CTICU. The alarms observed were Apnea, High $\mathrm{P}_{\mathrm{aw}}$, High awRR, Low PEEP, Low/High $\dot{\mathrm{V}}_{\mathrm{E}}$, and
Inspiratory Flow Overrange (Table 5). The 2-proportion ztest was statistically significant for differences in ventilator alarm proportions with both ventilators combined (Avea and Servo-i) and all 6 types of alarms compared. However, when testing for the Servo-i only, the Low PEEP alarm was not statistically significant. The other 5 alarms showed a statistically significant difference in proportions between 


\section{Ventilator Alarms in Pediatric Intensive Care}

Table 5. 2-Proportion z-Test for Ventilator Alarms Between Pediatric ICU and Cardithoracic ICU

\begin{tabular}{|c|c|c|c|c|c|c|}
\hline Alarm Type & $\begin{array}{l}\text { Avea and Servo-i } \\
\text { Ventilators }\end{array}$ & $\begin{array}{l}\text { Pediatric ICU } \\
\text { Alarm, } \%\end{array}$ & $\begin{array}{c}\text { Cardiothoracic ICU } \\
\text { Alarm, } \%\end{array}$ & $\begin{array}{c}\text { Servo-i Ventilator } \\
\text { Only }\end{array}$ & $\begin{array}{l}\text { Pediatric ICU } \\
\text { Alarm, } \%\end{array}$ & $\begin{array}{c}\text { Cardiothoracic ICU } \\
\text { Alarm, } \%\end{array}$ \\
\hline Apnea & $<.001$ & 9 & 5 & $<.001$ & 10 & 5 \\
\hline High $\mathrm{P}_{\mathrm{aw}}$ & $<.001$ & 11 & 20 & $<.001$ & 14 & 20 \\
\hline High awRR & $<.001$ & 18 & 17 & $<.001$ & 19 & 17 \\
\hline Low PEEP & $<.001$ & 9 & 8 & .13 & 8 & 8 \\
\hline Low/High $\dot{\mathrm{V}}_{\mathrm{E}}$ & $<.001$ & 7 & 4 & $<.001$ & 9 & 4 \\
\hline $\begin{array}{l}\text { Inspiratory Flow } \\
\text { Overrange }\end{array}$ & $<.001$ & 30 & 45 & $<.001$ & 40 & 45 \\
\hline \multicolumn{7}{|c|}{$\begin{array}{l}\text { Data are presented as } P \text { values and percentage of total alarms. } \\
\mathrm{P}_{\mathrm{aw}}=\text { high peak inspiratory pressure } \\
\text { awRR = airway respiratory rate (breathing frequency) } \\
\dot{\mathrm{V}}_{\mathrm{E}}=\text { minute ventilation }\end{array}$} \\
\hline
\end{tabular}

Table 6. Proportion of Alarms Caused by Ventilators in the Hospital Setting

\begin{tabular}{llc}
\hline \hline \multicolumn{1}{c}{ Study } & Population Type & $\begin{array}{c}\text { Proportion of } \\
\text { Clinical Alarms } \\
\text { Caused by Ventilators }\end{array}$ \\
\hline${\text { O’Carroll }(1986)^{10}}_{\text {Lawless }(1994)^{7}}$ & Operating Room & $45 \%$ \\
Chambrin et al (1999) & Pediatric ICU & $31 \%$ \\
Schmid et al $(2011)^{3}$ & Adult ICU & $38 \%$ \\
& Operating Room & $16 \%$ \\
\hline
\end{tabular}

both areas with the Servo-i only $(P<.001)$ (Table 5). The only notable similarity between the 2 alarm frequencies in the PICU and CTICU was the Low PEEP when controlling for Servo-i only ventilators.

\section{Discussion}

The studies by Schondelmeyer et al, ${ }^{18}$ Schmid et al, ${ }^{19}$ and Bridi et $\mathrm{al}^{20}$ maintained the idea that clinical alarms as a group occur at a high rate. Many studies also demonstrated a high incidence of nonactionable alarms. ${ }^{7,8,14,21}$ Researchers have studied the overall frequency of clinical alarms and the proportion of nonactionable alarms, but the specific causes and types were not well understood..$^{7,8,18-20,22}$ In addition, the proportion of clinical alarms due to ventilator alarms ranged from $16 \%$ to $45 \%$ and is a significant segment of all clinical alarms (Table 6). ${ }^{3,7,10,11}$

\section{Ventilator Alarm Prevalence Rates}

The overall ventilator alarm prevalence rate measured in our study was 22.5 alarms per day of mechanical ventilation per patient. Our result was slightly higher than an earlier study in the PICU setting by Lawless, who reported 17.5 alarms per day of mechanical ventilation. ${ }^{7}$ The study by Lawless et $\mathrm{al}^{7}$ was one of the few studies of ventilator alarm rates in the PICU setting. More recently published studies in the PICU population were unavailable for comparison of ventilator alarm prevalence rates (Table 7 for comparison on ventilator alarm prevalence rates).

Earlier studies in the adult ICU population by Chambrin et $\mathrm{al}^{11}$ and Trojanowski et $\mathrm{al}^{25}$ also reported lower ventilator alarm prevalence rates of 14.8 and 16.2 ventilator alarms per ventilator day, respectively. However, a more recent adult ICU study by Cvach et $\mathrm{al}^{27}$ reported prevalence rates of 168 ventilator alarms per day of mechanical ventilation. Another recent study by Belteki et $\mathrm{al}^{28}$ in a neonatal ICU setting reported a significantly higher prevalence rate of 240 ventilator alarms per day of mechanical ventilation. The study by Belteki et $\mathrm{al}^{28}$ was performed with the Dräger Babylog VN500 ventilator, whereas the study by Cvach et $\mathrm{al}^{27}$ used the Hamilton G5 and PB840 ventilators.

The 10-fold increase in ventilator alarm prevalence rates reported in more recent studies may be related to differences in critical care ventilators, patient populations, or patient care settings. Newer ventilators are generally equipped with additional modes, complex algorithms, and capability to monitor additional parameters. Our own study identified a statistically significant $(P<.001)$ difference in alarm proportions in different types of alarms when comparing the Servo-i and Avea ventilators between the PICU and CTICU (Table 5). For example, apnea alarms occurred at twice the rate in the PICU compared to the CTICU. This may have been due to the different underlying diseases in each ICU. Clearly, alarm prevalence rates varied between the different types of ventilators and care settings.

\section{Medium- and High-Priority Alarms}

The AARC consensus report classified common ventilator alarm conditions into Level 1 and Level 2 priority alarms using the AARC alarm priority criteria. ${ }^{16}$ Level 1 priority alarms are considered immediately life-threatening, such as apnea. Level 2 priority alarms are defined as potentially lifethreatening events; immediate intervention recommended 
Ventilator Alarms in Pediatric Intensive Care

Table 7. Rates of Ventilator Alarms in Adult, Pediatric, and Neonatal Populations

\begin{tabular}{|c|c|c|c|}
\hline Study & Duration of Observation & Population Studied & Incidence Rate* \\
\hline Lawless $(1994)^{7}$ & $928 \mathrm{~h}$ & Pediatric ICU & 17.5 \\
\hline Chambrin et al (1999) $)^{11}$ & $1,971 \mathrm{~h}$ & Adult ICUs & 14.8 \\
\hline Evans et al $(2005)^{23}$ & $60,240 \mathrm{~h}$ & Adult ICUs & $\begin{array}{l}1.3 \text { (alerts for ventilator disconnect } \\
\text { alarm only) }\end{array}$ \\
\hline Gorges and Westenskow $(2009)^{24}$ & $\begin{array}{l}200 \mathrm{~h} \\
556 \text { vent alarms }\end{array}$ & Adult ICU & 66.7 \\
\hline Trojanowski and Cvach $(2014)^{25}$ & $\begin{array}{c}10 \text { weeks } \\
1,709 \mathrm{~d} \text { of mechanical ventilation } \\
27,607 \text { alarms }\end{array}$ & Adult ICU & 16.2 (5.8 with alarm delay) \\
\hline Belteki $(2017)^{26}$ & $2,760 \mathrm{~h}$ & Neonatal ICU & 240.0 \\
\hline Stokes et al $(2017)^{2}$ & Not available & Adult ICU & 71.4-571.4 ventilator alarms/ICU day \\
\hline Cvach et al $(2018)^{27}$ & $18 \mathrm{~d}$ & Adult ICU & 168 (7.0 alarms per ventilator hour) \\
\hline
\end{tabular}

for both types of priority alarms. ${ }^{16}$ Ventilator manufacturers' interpretation of the expert panel recommendations classified the ventilator alarms as high-priority or medium-priority alarms for the Servo-i and Avea ventilators.

Our results indicate that the Avea ventilator had a greater proportion of high priority alarms (84\%), whereas the Servo-i exhibited more medium-priority alarms (69\%). In contrast, the study by Cvach et $\mathrm{al}^{27}$ reported that $90 \%$ of alarms from the Hamilton G5 were high-priority alarms, compared with $9 \%$ from the PB840 ventilators. It is clear that manufacturers' interpretations of alarm priority vary. In our comparison of the Avea and Servo-i manufacturer alarm priority (Table 2), a disagreement was found on alarm classifications for PEEP and High $\dot{V}_{E}$. There was agreement, however, with Apnea, High $\mathrm{P}_{\mathrm{aw}}$, Respiratory Rate, and Low $\dot{\mathrm{V}}_{\mathrm{E}}$ alarms. The disagreement in alarm priority classification between manufacturers accounted for some of the differences in alarm priority proportions between these 2 ventilators. Alarm priority ratings require further standardization to improve agreement and consistency between manufacturers.

\section{Manufacturer Preset Algorithms}

Our study identified 2 proprietary manufacturer alarms, the Inspiratory Flow Overrange alarm $(42 \%)$ on the Servo-i and the Circuit Integrity alarm $(20 \%)$ on the Avea, as 2 of the most common alarms based on the type of ventilator. These alarms were preset according to manufacturer algorithms. The high proportions of these alarms suggests that preset algorithms may not be ideal for all pediatric conditions. Flow and volume demands can vary widely in the pediatric population based on patient size and disease state. The condition of uncuffed endotracheal tubes, airway leaks, smaller tidal volumes, use of external flow sensors, and interactions with humidity and circuit rainout add to the challenges in ventilator alarm management in the pediatric patient. Alarm algorithms designed by ventilator manufacturers vary between the adult, pediatric, and neonatal modes and between types of ventilator. The high proportion of Inspiratory Flow Overrange and Circuit Integrity alarms suggests that additional capabilities for alarm customization are needed to optimize alarm parameters and reduce the overall alarm prevalence.

\section{Most Prevalent Ventilator Alarms}

In our study, the Inspiratory Flow Overrange (42\%), high awRR (18\%), and High $\mathrm{P}_{\mathrm{aw}}(17 \%)$ alarms were the most prevalent type of alarms. These findings were consistent with some of the findings reported by Tan et $\mathrm{al}^{26}$ and by Cvach et al. ${ }^{27}$ Tan et $\mathrm{al}^{26}$ reported high $\mathrm{P}_{\mathrm{aw}}$, high breathing frequency, high $\mathrm{V}_{\mathrm{T}}$, high $\dot{\mathrm{V}}_{\mathrm{E}}$, and low $\mathrm{P}_{\mathrm{aw}}$ to be some of the most common alarms in adult ICUs. Cvach et $\mathrm{al}^{27}$ also studied the frequency of ventilator alarms extensively in an adult intensive care setting and reported the proportion of ventilator alarms to be greatest with the high peak inspiratory pressure $(34 \%)$, high breathing frequency $(18 \%)$, and low $\mathrm{V}_{\mathrm{T}}(13 \%)$.

No pediatric studies were found for comparison of ventilator alarm proportions; however, in a neonatal ICU study, Belteki et $\mathrm{al}^{28}$ reported variations in breathing frequency and $\dot{\mathrm{V}}_{\mathrm{E}}$ as the primary determinants for ventilator alarm activation. The studies by Tan et $\mathrm{al}^{26}$ and $\mathrm{Cvach}$ et $\mathrm{al}^{27}$ indicated that high $\mathrm{P}_{\mathrm{aw}}$ and high breathing frequency alarms were some of the most common causes for ventilator alarms in the adult population. These findings were consistent with our results for High awRR and High $\mathrm{P}_{\mathrm{aw}}$ alarms, which were identified as 2 of the 3 most common causes for ventilator alarms. The Inspiratory Flow 


\section{Ventilator Alarms in Pediatric Intensive Care}

Table 8. Ventilator Alarms Description

\begin{tabular}{|c|c|}
\hline Alarm Name & General Alarm Description \\
\hline Apnea & Triggered if the ventilator does not detect a breath initiation within the preset period of time. \\
\hline Circuit Integrity & $\begin{array}{l}\text { This alarm is unique to the Avea ventilator and activated if the peak pressure exceeds the target peak pres- } \\
\text { sure by } 10 \mathrm{~cm} \mathrm{H}_{2} \mathrm{O} \text {, or } 15 \% \text { in adult/pediatric mode (whichever is greater); or by } 5 \mathrm{~cm} \mathrm{H}_{2} \mathrm{O} \text {, or } 15 \% \text { in } \\
\text { neonate mode, above the target peak pressure (whichever is greater). }\end{array}$ \\
\hline High Tidal Volume & $\begin{array}{l}\text { Activated if the absolute monitored exhaled tidal volume is greater than the High Tidal Volume threshold } \\
\text { setting; the high tidal volume alarm is not present on the Servo-i ventilator. }\end{array}$ \\
\hline Low $P_{\text {peak }}$ & $\begin{array}{l}\text { Activated whenever the peak inspiratory pressure for a given breath is less than the preset threshold for Low } \\
\mathrm{P}_{\text {peak }} \text {; this alarm is not available on the Servo-i. }\end{array}$ \\
\hline Low $\mathrm{V}_{\mathrm{TE}}$ & $\begin{array}{l}\text { Activated whenever the absolute monitored exhaled tidal volume does not exceed the Low Tidal Volume } \\
\text { alarm threshold setting for the Low } \mathrm{V}_{\mathrm{TE}} \text { Sensitivity setting; this alarm is not on the Servo-i alarm. }\end{array}$ \\
\hline $\mathrm{P}_{\mathrm{aw}}$ High & Triggered whenever the preset High $\mathrm{P}_{\text {peak }}$ threshold is exceeded. \\
\hline Low PEEP & $\begin{array}{l}\text { Activated if the baseline pressure (PEEP) is less than the Low PEEP alarm threshold for a period greater } \\
\text { than } 0.25 \pm 0.05 \text { seconds in the Avea. In the Servo-i, this alarm is activated when the measured PEEP is } \\
\text { below the set alarm or default alarm limit for three breaths. }\end{array}$ \\
\hline High Respiratory Rate (High AwRR) & This is activated if the monitored breaths exceed the set high respiratory rate alarm setting. \\
\hline High $\dot{\mathrm{V}}_{\mathrm{E}}$ & Activated whenever the monitored exhaled minute volume is greater than the High $\dot{\mathrm{V}}_{\mathrm{E}}$ threshold setting. \\
\hline Low $\dot{V}_{\mathrm{E}}$ & Activated whenever the monitored exhaled minute volume is less than the Low $\dot{V}_{\mathrm{E}}$ threshold setting. \\
\hline Inspiratory Flow Overrange & $\begin{array}{l}\text { This alarm is unique to the Servo-i and activated when a combination of parameter settings exceeds the } \\
\text { allowable inspiration flow range (Adult: } 0-3.3 \mathrm{~L} / \mathrm{s} \text {; Infant: } 0-0.55 \mathrm{~L} / \mathrm{s} \text { ). }\end{array}$ \\
\hline$\dot{\mathrm{V}}_{\mathrm{E}}=\mathrm{n}$ & \\
\hline
\end{tabular}

Overrange alarm, specific to the Servo-i, was difficult to compare to other studies as no other Servo-i alarm data were reported.

\section{Strategic Reduction of Ventilator Alarms}

A systematic analysis of ventilator alarm data is an important first step in a logical and strategic approach to ventilator alarm reduction. This comprehensive method quantifies and helps prioritize the most prevalent types of alarms specific for each ventilator. A secondary step is to evaluate the institutional policy and consider whether guidelines for ventilator alarm management provide adequate guidance for all common alarms. A standard policy is necessary for consistent practice and could have a meaningful impact in reducing alarm prevalence. However, in a systematic review of issues related to ventilator alarms and alarm fatigue, Scott et $\mathrm{al}^{17}$ found no published standard guideline for clinicians and institutions to follow when setting ventilator alarm parameters.

Very little data are available to guide best practices for setting ventilator alarm limits. Furthermore, the lack of information on alarm management practices and outcomes makes comparisons with other institutions difficult. This necessitates internal benchmarking of baseline alarm prevalence rates followed by methodical policy changes to reduce alarms and efforts to compare resulting changes to previous alarm prevalence rates. This systematic method for benchmarking and analysis of alarm prevalence rates will bring the profession closer to a logical, evidence-based approach to setting ventilator alarms (Table 8). ${ }^{29,30}$

The high prevalence measured with some alarms suggested room to customize alarm parameters selectively based on the type of alarm priority and redundancy. Trojanowski et $\mathrm{al}^{25}$ reported that adding an alarm delay of $5 \mathrm{~s}$ could reduce the overall ventilator alarm prevalence by $64 \%$. In our study, the top 5 alarms accounted for $>85 \%$ of all alarms generated; therefore, a focused approach with the top 5 alarms may have a significant impact. Lastly, educating end users to alarm algorithms inherent to each alarm is essential. The most common alarm found in our study, the Inspiratory Flow Overrange alarm, was not directly set by the practitioner. A greater understanding of the underlying relationships, such as manufacturer-designed flow limitations programmed for each mode of ventilation, is essential to reducing the conditions activating this alarm.

\section{Limitations}

Currently, there is no standardized metric or method for reporting ventilator alarm rates. The reported rates in our study (Table 3) were converted to the number of ventilator alarms per ventilator day per patient to facilitate comparisons in prevalence rates. Some studies excluded their number of ventilator days or other types of ventilator alarms in which only high-priority alarms were reported., ${ }^{2,23}$ This made it difficult to standardize the ventilator alarm 


\section{Ventilator Alarms in Pediatric Intensive Care}

prevalence rate for comparison with other research findings. In addition, the ventilator manufacturer and model were often not reported, which made ventilator-specific comparisons difficult to perform.

An additional challenge in ventilator alarm comparisons was the use of ventilator alarm terminology specific to the manufacturer's preference. The varied names for similar alarm conditions made comparisons more difficult. Attempts were made maintain the manufacturer's preferred terms for consistency. The unique ventilator alarms of the Avea device (ie, Circuit Integrity alarm) and the Servo-i ventilator (ie, Inspiratory Flow Overrange alarm) added another level of difficulty to our comparisons.

A clear methodology for comparison and benchmarking of ventilator alarm rates requires that all of the different types of alarms are captured and considered in the context of the total duration of mechanical ventilation for the time period being compared. The method applied in this study captured the diverse type of alarms prevalent in the PICU and CTICU in addition to the total days of mechanical ventilation. However, we could not gather alarm data from specialized ventilators such as the Sensormedics 3100a and $3100 \mathrm{~b}$, as well as home mechanical ventilators, due to software and hardware connectivity issues.

The collection of a large sample size is difficult due to limitations in the information technology and connectivity infrastructure. The automated process for electronically collecting ventilator alarm characteristics allows for the detailed examination of large data, which provides a comprehensive portrayal of ventilator alarm patterns in the clinical setting.

Generalization with this study is limited. First, the data studied were limited to the type of medical devices and monitors available at Children's Hospital Los Angeles. Second, this study looked at only 2 types of ventilators. There are many other types of pediatric ventilators used throughout other ICUs. An observational study specific to each type of ventilator is needed to fully account for the variations in ventilator algorithms. Third, the detailed ventilator days attributed to each type of ventilator model were not collected for this study. This limits the ability to compare alarm prevalence rates specific to each type of ventilator. Additionally, ventilator alarm data collection was limited by the middleware system. Some alarms such as the high and low $\dot{V}_{\mathrm{E}}$ on the Servo-i were bundled together due to system programming design. Lastly, the prevalence of ventilator alarms needs to be considered in the context of institutional alarm management practices.

\section{Conclusions}

The lack of ventilator alarms research in the pediatric population makes it compelling to do research for this vulnerable population. Studying the type and prevalence of ventilator alarms within the context of alarm management policies and guidelines in the clinical setting will help direct the professional community toward an evidence-based approach to alarm management.

Ventilators are designed to have their own unique alarm pattern and algorithms that impact alarm frequency and proportionality. Ventilator alarms occurred in the PICU and CTICU in a large metropolitan children's hospital at an average combined prevalence rate of 22.52 ventilator alarms per day of mechanical ventilation per patient. Overall, the most common ventilator alarms were the Inspiratory Flow Overrange (37\%), High awRR (18\%), and High $\mathrm{P}_{\mathrm{aw}}(15 \%)$. Alarm characteristics vary with different ventilators. Ventilator alarm proportions also varied significantly between the PICU and the CTICU. Ventilator alarm proportions were significantly different between the Avea and Servo-i ventilators. Lastly, classification of high- and medium-priority alarms varies between ventilator manufacturers.

More studies are needed to observe the behavior of each type of ventilator within different patient populations, disease states, alarm parameter guidelines, and hospital settings. Lastly, connecting the alarms to physiological responses, patient interventions and outcomes can help the medical community identify the most important alarms, and which might play a secondary role. Ventilator manufacturers can design more effective and meaningful alarm systems with this new information.

\section{REFERENCES}

1. Welch M, Kanter B, Bagian T, Jacobs K, Shanawani H, Jaffe R. Framework for alarm management process maturity. Biomedical Instrumentation \& Technology 2016:165-179.

2. Stokes J, Manzoor S, Cvach M. Ventilator alarms: challenges and opportunities for improvement. Biomed Instrum Technol 2017;51 (5):390-397.

3. Schmid F, Goepfert M, Kuhnt D, Eichhorn V. The wolf is crying in the operating room: patient monitor and anesthesia workstation alarming patterns during cardiac surgery. Anesth Analg 2011;112(6):78-83.

4. Bonafide C, Lin R, Zander M, Graham CS, Paine CW, Rock W, et al. Association between exposure to nonactionable physiogic monitor alarms and response time in a children's hospital. J Hosp Med 2015;10 (6):345-351.

5. Siebig S, Kuhls S, Imhoff M, Gather U, Scholmerich J, Wrede C. Intensive care unit alarms-how many do we need? Crit Care Med 2010;38(2):451-456.

6. Graham KC, Cvach M. Monitor alarm fatigue: standardizing use of physiological monitors and decreasing nuisance alarms. Am J Crit Care 2010;19(1):28-34.

7. Lawless ST. Crying wolf: false alarms in a pediatric intensive care unit. Crit Care Med 1994;22(6):981-985.

8. Sendelbach S, Funk M. Alarm fatigue: a patient safety concern. AACN Adv Crit Care 2013;24(4):378-386.

9. AAMI. 2015 Alarm management compendium. Available at: https:// www.aamifoundation.org/wp-content/uploads/2018/11/alarm compendium_2015.pdf. Accessed October 26, 2019.

10. O'Carroll TM. Survey of alarms in an intensive therapy unit. Anaesthesia 1986;41(7):742-744. 


\section{Ventilator Alarms in Pediatric Intensive Care}

11. Chambrin M, Ravaux P, Calvelo-Aros D, Jaborska A, Chopin C, Boniface B. Multicentric study of monitoring alarms in the adult intensive care unit (ICU): a descriptive analysis. Intensive Care Med 1999;25(12):1360-1366.

12. ECRI. Top 10 health technology hazards for 2020. Available at: https://www.ecri.org. Accessed November 3, 2019.

13. Joint Commission. The Joint Commission Sentinel Event Alert on Alarms. Available at: https://www.jointcommission.org. Accessed April 26, 2016.

14. Love LCDR, Millin CJ, Kerns CDRC. Take precautions with audible alarms on ventilators. Nursing 2011;41(9):65.

15. The Joint Commission. Zero harm: an achievable goal. Healthcare Executive 2018:70-73.

16. Consensus statement on the essentials of mechanical ventilators-1992. American Association for Respiratory Care. Respir Care 1992;37 (9):1000-1008.

17. Scott J, De Vaux L, Dills C, Strickland S. Mechanical ventilation alarms and alarm fatigue. Respir Care 2019;64(10):1308-1313.

18. Schondelmeyer A, Bonafide C, Goel V, Blake N, Cvach M, Sucharew $\mathrm{H}$, et al. The frequency of physiologic monitor alarms in a children's hospital. J Hosp Med 2016;11(11):796-798.

19. Schmid F, Goepfert M, Reuter D. Patient monitoring alarms in the ICU and in the operating room. Crit Care 2013;17(2):216.

20. Bridi A, da Silva R, de Farias C, Franco A, dos Santos V. [Reaction time of a health care team to monitoring alarms in the intensive care unit: implications for the safety of seriously ill patients]. Rev Bras Ter Intensiva 2014;26(1):28-35.

21. Ahlborn V, Bohnhorst B, Peter CS, Poets CF. False alarms in very low birth weight infants: comparison between three intensive care monitoring systems. Acta Paediatr 2000;89(5):571-576.
22. Schmid F, Goepfert M, Franz F, Laule D, Reiter B, Goetz A, et al. Reduction of clinically irrelevant alarms in patient monitoring by adaptive time delays. J Clin Monit Comput 2017;31(1):213-219.

23. Evans R, Johnson K, Flint V, Kinder T, Lyon C, Hawley W, et al. Enhanced notification of critical ventilator events. J Am Med Inform Assoc 2005;12(6):589-595.

24. Gorges M, Markewitz BA, Westenskow DR. Improving alarm performance in the medical intensive care unit using delays and clinical context. Anesth Analg 2009;108(5):1546-1552.

25. Trojanowski M, Dela Paz A, Cvach M, Sapirstein A. Characterizing the frequency, duration, and functionality of mechanical ventilator alarms. Respir Care 2014;59(10):OF56.

26. Tan W, Qin Z. The comparative analysis of the common reasons of invasive ventilator alarms between medical and specialist intensive care unit. Zhongguo Wei Zhong Bing Ji Jiu Yi Xue 2012;24(10):582586.

27. Cvach M, Stokes J, Manzoor S, Brooks P, Burger T, Gottschalk A, Pustavoitau A. Ventilator alarms in intensive care units: frequency, duration, priority, and relationship to ventilator parameters. Anesth Analg 2020;130(1):e9-e13.

28. Belteki G, Morley CJ. Frequency, duration and cause of ventilator alarms on a neonatal intensive care unit. Arch Dis Child Fetal Neonatal Ed 2018;103(4):F307-F311.

29. Carefusion. AVEA Ventilator Systems Operator's Manual. In (Revision H ed., Vol. Literature number: L2786 Revision H): Carefusion; 2010.

30. Maquet. Ventilator System SERVO-i V5.0. In M. Corporation (Ed.), (Version 3 ed., Vol. Order No: 6675795 User's Manual): Maquet Critical Care;2010.

This article is approved for Continuing Respiratory Care Education credit. For information and to obtain your CRCE

(free to AARC members) visit

www.rcjournal.com 